\title{
Padre Raphael Maria Galanti: intelectual e historiador jesuíta
}

\author{
Father Raphael Maria Galanti: intelectual and Jesuit historian
}

\author{
Ligia Bahia de Mendonça
}

Prefeitura da Cidade do Rio de Janeiro ligiabahia@gmail.com

Resumo: A educação foi uma das pedras fundamentais da Companhia de Jesus. Dedicada principalmente aos jovens, com colégios fundados por todo mundo, a Ordem foi extinta em 1759, como uma das consequências da Reforma Pombalina. Em 1814, no entanto, a Companhia foi restaurada pelo Papa Pio VII, que assinou a Bula Papal reconstituindo a Ordem Inaciana e possibilitou a reabertura das suas instituições de ensino. Apoiamo-nos no conceito de rede de sociabilidade de JeanFrançois Sirinelli, que se refere à forma como essa rede se constitui, seja geográfica ou afetivamente; como esses intelectuais se congregam, nas suas adesões e rejeições; quais seus itinerários e como influenciaram a escrita da História do Brasil. A Companhia de Jesus foi representada pelo Padre Raphael Maria Galanti. Assim, nosso objetivo é resgatar a trajetória do padre Galanti, vista do "ângulo morto" a que se refere Sirinelli, até mesmo dentro da própria Companhia de Jesus, tratando-o como objeto de estudo.

Palavras Chaves: Intelectual, Companhia de Jesus, Livro Didático, Pensamento Historiográfico Brasileiro.

\begin{abstract}
Education was one of the cornerstones of the Companhia de Jesus. Dedicated mainly to young people, with schools worldwide, the Order was abolished in 1759, as one of the consequences of Pombal Reforms. In 1814, however, the Company was restored by Pope Pius VII, who signed the Bull reconstituting the Ignatian Order, which allowed the reopening of their schools. We rely on the concept of network sociability proposed by JeanFrançois Sirinelli, which refers to the ways that network constitutes itself, either geographically or affectively; how these intellectuals congregate in their approaches and rejections; what were their itineraries and how they influenced the writing of the History of Brazil. In this, Companhia de Jesus was represented by Fr. Raphael Maria Galanti. So our aim is to rescue the career of Fr. Galanti, view from the "blind spot" that was referred by Sirinelli, even within the Companhia de Jesus, and treating him as an object of study.
\end{abstract}

Keywords: Intellectuals, Companhia de Jesus, Textbook, Brazilian historiography. 
O intelectual é filho do seu tempo. Escreve, analisa e interpreta a partir do seu tempo vivido, das suas experiências e de sua formação teórico- metodológica, ou, por que não de vida? Refletir sobre o padre jesuíta Raphael Maria Galanti, sob esta perspectiva, é o horizonte desta escrita.

No entanto, diante dos debates em torno da História dos intelectuais, com maiúscula, conforme aponta-nos Jean-François Sirinelli, tão em voga na atualidade, visto que esta história já foi compreendida e estudada como algo menor, notamos que a história política dos intelectuais está vinculada à pesquisa e à exegese dos textos, principalmente os de natureza impressa, que são suporte "dos fatos de opinião", "em cuja gênese, circulação e transmissão os intelectuais desempenham um papel decisivo" (SIRINELLI, 2003: 245). O autor indica uma proposta acerca da história do intelectual, a saber: a elaboração a partir de "uma observação baseada na circulação - e no degradé - entre os três níveis - ideologia, cultura política e "mentalidades coletivas". Constituindo, portanto, um procedimento, que torna viável partir do papel cultural e político do intelectual para abarcar "uma história política transformada em história global [...]" (SIRIENELLI, 2003: 262).

Desta forma, descortinamos o intelectual conhecido pelos seus livros didáticos de História, o retiramos do "ângulo morto" da história. Mas, quem é o intelectual que escreve? Qual seu itinerário? Qual o significado de ser um jesuíta na sua escrita ou na vida intelectual? Faria Galanti parte de uma geração do pensamento historiográfico brasileiro do século XIX e XX?

\section{Olhares sobre Raphael Maria Galanti e seus livros de história}

Buscamos um percurso sobre a relevância da História do livro para o campo historiográfico, visto que são os livros do padre Raphael Maria Galanti nos dão a base material para a reflexão sobre dois conceitos históricos que consideramos fundamentais, a saber: rede de sociabilidade e itinerário. Roger Chartier (1996) e Robert Darnton (1990) são os principais expoentes da história do livro e das práticas de leitura, com os quais dialogamos neste trabalho. Destacamos dois autores, entre tantos outros no cenário 
internacional e nacional ${ }^{1}$, identificados com a História Cultural, de que são expoentes. Robert Darnton situa a história do livro com o surgimento da imprensa:

\begin{abstract}
Alguns historiadores do livro buscam seu objeto no período anterior à invenção do tipo móvel. Alguns estudiosos da imprensa se concentram em jornais, folhetos e outras formas além do livro. Pode-se estender e ampliar o campo de muitas maneiras, mas de modo geral ele trata de livros desde a época de Gutemberg, sendo uma área da pesquisa que se desenvolveu com tanta rapidez nos últimos anos que é provável que conquiste um lugar ao lado de campos como a história da ciência e a história da arte, no elenco das disciplinas acadêmicas (1990: 109).
\end{abstract}

Os primeiros estudos voltados para o livro como objeto material surgem na Inglaterra, no século XIX. Porém, foi na França, na década de 1960, que se ampliou o estudo histórico, com "novos objetos, novos problemas e novas abordagens" (DARNTON, 1995: 109-112). Inserido nessa conjuntura, surge o estudo do livro como objeto de pesquisa: "um objeto comum e uma narrativa singular, ligando a particularidade de uma história e a banalidade de uma forma, pondo como questão central os efeitos desejados ou produzidos através da apresentação impressa de tal narrativa" (CHARTIER, 1990: 86). Para Frade e Maciel (2006), a análise do livro deve ir além do seu conteúdo, é necessário percorrer todo movimento editorial. O mesmo posicionamento é encontrado em Fernandes e Felgueiras (2000), que nos falam da relevância de notar descrições físicas, validação e difusão. Novamente nos apropriamos de Chartier:

A questão essencial que, na minha opinião, deve ser colocada por qualquer história do livro, da edição e da leitura é a do processo pelo qual os diferentes atores envolvidos com a publicação dão sentidos aos textos que transmitem, imprimem e leem. Os textos não existem fora dos suportes materiais (sejam eles quais forem) de que são os veículos. Contra a abstração dos textos, é preciso lembrar que as formas que permitem sua leitura, sua audição ou sua visão participam profundamente da construção de seus significados (2002: 62).

\footnotetext{
${ }^{1}$ Como nos sugere Villalta (2001), citando outros intelectuais como: no exterior, Carlo Ginzburg, Natalie Zemon Davis e Rita Marquilhas; no Brasil, Maria Beatriz Nizza da Silva, Lúcia Maria B. P. das Neves, Tânia Bessone Ferreira, Maria Lajolo e Regina Zilberman.
} 
Tendo nas mãos os livros do padre Galanti, e a partir de uma investigação detalhada que dialogue com a história do livro e da leitura, buscamos percebê-lo como intelectual. Dentro deste objetivo, também nos utilizamos da micro-história como metodologia de pesquisa que, por meio de jogos de escalas, nos coloca diante de possíveis apreensões de aspectos que, a priori, poderiam nos passar despercebidos, mas que se tornam reveladores para investigação de um problema ou questão, seja no nível cultural ou social.

A circulação dos livros de Galanti exerce uma função de defesa da ordem, de convencimento de ideias sobre o Brasil, um convite para a reflexão acerca da importância da educação como lócus de formação do homem.

A história do livro didático como documento e objeto de investigação histórica tem se mostrado relevante nos últimos anos. Com a perspectiva de dar a ver esses vieses, apresentamos cinco pesquisas, a saber: A historiografia amadora de Rocha Pombo: embates e tensões na produção historiográfica brasileira da Primeira República, de Ivan Norberto dos Santos (2009), "Laudo ou Sentença? A decisão de Pedro Lessa da data comemorativa da Confederação do Equador”, de Aline Michelini Menoncello (2013), “A questão racial no ensino secundário baiano: problematizando o livro didático de história”, de Maria Cristina Dantas Pina (2006), O personagem negro em lições de história no Brasil: olhares oitocentistas, de Maria Lígia Conti (2011), e O século XIX e a escrita da história do Brasil: diálogos na obra de Tristão de Alencar Araripe (1867-1895), de Hugo Hruby (2012). Pelo viés que nos interessa, esses estudos enfocam o padre Raphael Maria Galanti e seus livros. Também é relevante notar como Galanti é analisado, ou seja, como intelectual ou autor nas diversas áreas. Ressaltamos, porém, que nenhuma dessas pesquisas discute especificamente o intelectual analisado no presente artigo. Destaco que são matizes que ora se aproximam, ora se afastam do padre Galanti.

Em A historiografia amadora de Rocha Pombo: embates e tensões na produção historiográfica brasileira da Primeira República, Santos (2009) discutiu as longas citações retiradas dos livros de Galanti e as ironias com que Rocha Pombo as refere: as farpas lançadas, que dão ao leitor de Pombo a ideia de uma história amena demais para tratar de momentos "agitados" da história brasileira.

No artigo, "Laudo ou Sentença? A decisão de Pedro Lessa da data comemorativa da Confederação do Equador", Menoncello (2013) analisa as discordâncias em torno daquela data. Para tal, mostra-nos um jogo de poderes ou a tentativa de se estar no lugar de poder, por meio de alguns movimentos dos membros do Instituto Histórico e 
Geográfico Brasileiro (IHGB) e do Instituto Arqueológico e Geográfico de Pernambuco (IAGP). Dentre eles, destaca Oliveira Lima, que utiliza o autor jesuíta como autoridade para ratificar sua posição.

Já em “A questão racial no ensino secundário baiano: problematizando o livro didático de história”, Pina (2006) destaca, entre outros temas, como o livro didático enfocou a abolição da escravidão, citando, entre outros, Raphael Galanti:

Ao saberem da aprovação do projeto, as sociedades abolicionistas e o povo em geral invadiram o recinto das sessões, prorrompendo em entusiásticos aplausos. "Das tribunas, diz o historiador padre Raphael Galanti, caiam nuvens de flores; o pranto de alegria, os risos, as aclamações, as efusões irrompiam de toda parte" (PINA, 2006: 263).

A autora critica a escrita de Galanti sobre esse fato. Segundo ela, tais palavras “são responsáveis por reforçar o estabelecimento de mitos e heroísmos em personagens históricos como a Princesa Izabel. Não está presente aí a participação popular e dos próprios negros (escravos e libertos)" (PINA, 2006). Já na dissertação, cujo título é $O$ personagem negro em lições de história no Brasil: olhares oitocentistas, nota-se o esforço de Conti (2011) em pesquisar a presença do negro nos livros de lições de história dos idos de $1800^{2}$. Dentre os mesmos, mais uma vez, destacam-se os trabalhos do padre Galanti: Compêndio de História do Brasil, 1910; História do Brasil, 1911a; História do Brasil, 1911b; História do Brasil, 1913; Compêndio da História do Brasil, 1896, volume1. É relevante notar que a motivação de Conti foi a Lei n.10.639, de 2003, na qual se determinou o ensino da história e cultura africanas nas escolas brasileiras. Com isso, a referência ao padre objetivou encontrar material que trouxesse o conhecimento das relações sociais dos negros no tempo do tráfico negreiro e também nos movimentos pró e contra a escravidão, estendendo-se aos momentos de tensão, que levaram à assinatura da lei Áurea, que, libertando do cativeiro todos os negros, possibilitou que estes pudessem ser considerados cidadãos brasileiros, segundo a Constituição de 1891 (CONTI, 2011:

${ }^{2}$ Foram analisados os livros de: José Ignacio de Abreu e Lima, Raphael Maria Galanti, Joaquim Manuel de Macedo, Luis de Queirós Mattoso Maia, Américo Braziliense de Almeida e Melo, Alfredo Moreira Pinto, José Maria da Silva Paranhos Rio Branco Jr., Sylvio Roméro, João Ribeiro, Robert Southey, Francisco Adolfo de Varnhagen, João Barros, Diogo de Couto, J. da Cunha Barboza, Antonio de Paiva Guedes de Andrade. 
13). A partir daí, Conti pesquisa vários livros de história com intuito supracitado. Dentre os autores, destaca Raphael Maria Galanti, a quem descreve como

Italiano, branco. Padre Jesuíta, foi professor e autor de diversas obras reconhecidamente relevantes.

Galanti apresenta uma obra extensiva e sua habilidade na escrita é impressionante. $\mathrm{O}$ autor, ao longo de suas narrativas conduz o leitor a sentir com ele suas emoções.

Seu discurso é bastante religioso em muitos momentos. Defende-se com excelente argumentação de autores que o precederam, como Varnhagen, por exemplo, fazendo bom uso da vantagem de ser "posterior" àqueles que foram "agressores" dos jesuítas. Bastante didático - talvez o mais didático de todos os autores aqui consultados, explica, ilustra, exemplifica cada questão que possa parecer difícil ao seu leitor. Contudo, a obra está impregnada com sua religiosidade e as características circunstanciais que o cercam - trata-se de um jesuíta, educador, europeu, idoso, lecionando em salas de aula em escolas clássicas (CONTI, 2011: 90).

Partindo do caráter religioso da sua escrita, a autora destaca seus textos, tecendo críticas e elogios ao padre jesuíta. A primeira crítica refere-se à comparação que ele faz entre a escravidão indígena e africana. Para Conti, a respeito do negro Galanti destaca apenas o comércio e deixa de mencionar sua captura desenfreada; já ao tratar do índio, destaca que ele prezava pela sua liberdade e, por isso, teria sido mais difícil escravizá-lo; conforme podemos observar na escrita de Conti:

Porém, os negros, ao contrário do que se tem transmitido como informação histórica escolar, não foram fáceis de escravizar. Nas narrativas de livros de História, apreende-se a ideia de que os índios "amavam muito a liberdade, e sobre qualquer outra coisa receavam perdê-la”, como dirá Galanti (1910, p. 10-14), por isso não seriam facilmente escravizados; já os negros, dizia Las Casas, para eles "o cativeiro não prejudicava tanto a religião como o dos índios" (apud GALANTI, 1910, p. 10-14), o que sugere uma certa brandura por parte dos africanos, um conformismo em que somos levados a crer nos bancos escolares (assim como tenta justificar a omissão dos religiosos no apoio aos negros, em detrimento de sua luta pela liberdade dos índios) (CONTI, 2011: 33). 
Para a autora, o ensino jesuítico no Brasil Colônia foi marcado por um viés elitista e internacionalista. Sobre Galanti, destaca sua trajetória: o padre circulou por vários colégios jesuítas, Colégio dos Jesuítas de Desterro, em Florianópolis no ano de 1866, onde lecionou: grego, latim, geografia e história universal. Esteve também no Colégio São Luiz de Itu, em São Paulo, entre os anos de 1874 e 1876, onde ensinou filosofia e história eclesiástica. No Seminário de Belém, entre 1878 e 1880. Novamente em Itu, ensinou inglês, história universal e história do Brasil. Por fim, em 1898, foi para o Colégio Anchieta de Nova Friburgo, no Rio de Janeiro, onde lecionou história até ficar doente e falecer.

A autora aponta matizes relevantes para esta pesquisa a partir da perspectiva de ensino a que o autor dos livros didáticos de história se submeteu. Galanti adotou uma perspectiva de ensino que foi incorporada pelo corpo docente dos colégios em que lecionou. Conti faz duras críticas a Galanti: "No parágrafo sobre os Diamantes de Minas Gerais, Galanti mostra sua cara preconceituosa ao falar de Chica da Silva - não só seu preconceito é claro com relação à origem da mulher (ex-escrava), como evidentemente à própria questão do gênero" (CONTI, 2011: 92).

A autora ainda nos chama a atenção para sua habilidade na escrita, presente nos volumes 1 a 5 do Compêndio de História, enfatizando pontos de comparação com outros autores, tais como Américo Braziliense de Almeida e Melo e Francisco Adolfo de Varnhagen: "o autor esclarece, de forma bastante convincente, questões sobre as quais outros autores passam à margem ou dão informações que ele corrige, indicando fontes documentais" (CONTI, 2011: 92).

Ainda na análise de Conti, quando o padre discorre sobre o quilombo de Palmares e a morte do líder do movimento, Zumbi, no livro História do Brasil (Tomo II), se destaca pela grande habilidade na escrita e nos seus argumentos. Quando lhe paira a dúvida, recorre às fontes, aos documentos ou aos seus pares, o que lhe permite comprovar sua vocação para o ofício de historiador. Para Conti, no entanto, a conclusão é que: "Galanti não dá voz ao negro" (2011: 93), sendo esse tema o foco de seu trabalho.

Em O século XIX e a escrita da história do Brasil: diálogos na obra de Tristão de Alencar Araripe (1867-1895), Hugo Hruby refletiu sobre a produção da história no Oitocentos, cujo foco era a compreensão do que então tornava alguém historiador. Assim, considerava Araripe "um dos obreiros neste vasto canteiro em construção, representado principalmente pelo trabalho coletivo no Instituto Histórico e Geográfico Brasileiro (IHGB)" (HRUBY, 20012: s.n.). Nessa reflexão sobre a escrita da História, Hruby analisa 
os livros de padre Galanti com mais vigor, desde sua entrada no IHGB até os estudos historiógrafos de Galanti mais recentes.

A candidatura de Galanti no IHGB foi proposta por Alencar Araripe, em 13 de setembro de 1896. Sua obra Compêndio de História do Brasil, de 1911, volume 2, que abordou episódios do país até 1624, serviu como título de admissão. No entanto, a leitura e a reflexão para aceitação do novo sócio se resumiram ao primeiro tomo (MARQUES PINHEIRO, 1896: 276).

Hruby dedica-se à análise dos livros nos quais o padre se refere à História do Brasil, que somam um total de cinco volumes, e ainda ao sexto volume, sob o título As Biografias dos homens ilustres. Adentrando no texto do jesuíta, destaca a posição precavida de Galanti, tendo em vista que o levantamento e a leitura da bibliografia por este realizadas encobririam dificuldades, que envolviam o cotejamento de ampla bibliografia, bem como a falta de identificação das fontes. Hruby, cujo foco de estudo foi a escrita de Araripe, refere-se a seu emprego por outros autores, afirmando que, ao contrário de Rocha Pombo, por exemplo, Galanti as preteriu por pesquisas mais recentes.

Além disso, para o autor, "Galanti não se preocupou em explicitar o sentido dos acontecimentos, em apanhar o desdobramento de toda série de fatos capitais em um ciclo histórico. Da função educadora do autor nas escolas confessionais surgiu o resumo didático muito parcial" (HRUBY, 2012: 315).

O silêncio sobre a obra historiográfica do padre Galanti pode estar relacionado à produção de simples compêndios escolares, ausência de pesquisas em arquivos, não ser brasileiro para escrever a História do Brasil e por contrapor outro historiador de histórias gerais como estratégia de afirmação profissional num momento em que Varnhagen era resgatado (HRUBY, 2012: 315).

O “outro historiador" referido na tese é Tristão Alencar Araripe, a quem o padre jesuíta lança mão no seu livro, que reúne 433 biografias, onde "destacou-lhe por ser o filho do "malfadado presidente da República do Equador"3 (GALANTI, 1911a: 336-337). "Deteve-se na relação de suas funções parlamentares, burocráticas e participações em instituições culturais" (GALANTI apud HRUBY, 2012: 312), mencionando assim, em dois momentos, a obra de Araripe: "Sobre a questão da maioridade de D. Pedro II, foi

\footnotetext{
${ }^{3}$ Tristão Alencar Araripe era filho do coronel Tristão Gonçalves de Alencar Araripe, que foi um revolucionário da Confederação do Equador.
} 
apontada 'a bela dissertação' de Araripe publicada na Revista do IHGB, em 1881, e 'que nós aproveitamos sem escrúpulo"” (HRUBY, 2012: 314). E a narração sobre a Revolução Farroupilha de 1835, no Rio Grande do Sul, "que infelizmente contém muitas inexatidões" de Alencar Araripe, "em que se acham numerosos e interessantíssimos documentos" (HURBY, 2012: 314).

Abordamos essas pesquisas com intuito de endossar um movimento de garimpar pistas para a análise desenvolvida nesse artigo. Alguns autores que mencionamos rechaçaram e ironizaram as obras do padre, como é o caso de Rocha Pombo, no livro História do Brasil (1917a). Na leitura do prefácio de Compendio da História do Brasil (1910), Hruby mostra também o afastamento do padre de alguns autores contemporâneos: “Contudo, em grande parte do prefácio, Galanti se dedicou a ressaltar as suas discordâncias para com a síntese anterior de maior expressão: "pelo fato de termos aqui e ali confutado Varnhagen" (GALANTI apud HRUBY, 2012: 312).

Por outro lado, alguns intelectuais se apropriaram dos livros de Galanti, para dar propriedade às suas próprias pesquisas, como foi o caso de Oliveira Lima. Em artigo sobre a independência do Brasil para a Revista do Instituto Histórico e Geográfico Brasileiro (LIMA, 1918/1919: 351-426). Lima defendeu-se de duras críticas recebidas de Gonçalves Maia, que, em artigo no jornal A Província, com o título "O erro do Instituto Arqueológico", apontara a falta de documentos que comprovassem sua narrativa- para Gonçalves Maia, a História só poderia ser escrita a partir de documentos verdadeiros, os chamados "documentos positivos". Destacamos um trecho no qual Oliveira Lima apresentou um importante episódio da nossa história, sobre o qual negava haver documento positivo:

Em que data celebra o Brasil a sua independência? 7 de setembro, quando ressoou no Ipiranga a voz máscula de d. Pedro, ou a 12 de outubro, quando se verificou a aclamação imperial? O império, a nação independente, só começou oficialmente nesta última data [...]. Do grito do Ipiranga não existe senão a tradição histórica, variando mesmo nos pormenores. Não há ata, nem proclamação, nem manifesto d'aquele dia (LIMA apud MENONCELLO, 2013: 5).

Para exemplo tão contundente, apresentou autoridades, preferindo "regular-se pelo que pensam Varnhagen, Rio Branco, Pereira Pinto, Mello Moraes, Armitage, Galanti 
e Pereira da Costa" (MENONCELLO, 2013: 6). Assim, foi possível observar, portanto, num primeiro momento, o afastamento, a aproximação e o confronto de Galanti com certos autores e linhas de pensamento, o que constitui um dos focos de nossa reflexão.

O trabalho cujo objetivo principal é mostrar como o negro foi mencionado nos livros didáticos de História foi o mais crítico com relação a Galanti, no que concerne ao seu pensamento "preconceituoso", como cita a autora. Conti afirma-nos, ainda, depois de analisar diversos livros e autores em busca do seu objetivo principal supracitado, que "Os negros, como temos visto, não desfrutavam da atenção dos autores, mas houve quem aqui e ali, deixasse-lhes uma palavra de reconhecimento" (CONTI, 2011: 103).

A tese que analisa o IHGB refere-se à inscrição de Galanti nos institutos. Para Hurby, sua entrada no instituto do Rio de Janeiro fora uma questão de afirmação profissional. Ao problematizarmos, porém, esta questão, é possível sugerir que o intelectual buscasse maior visibilidade para sua obra, não para si, e sim para um corpo uno, do qual fazia parte, a Companhia de Jesus. Analisando-se a obra História do Brasil (tomo III), notamos que o padre faz várias referências às pesquisas do Instituto. Por exemplo, a um artigo da Revista do Instituto Histórico e Geográfico Brasileiro, quando se refere aos privilégios dos cidadãos do Rio de Janeiro, em 1642, então equiparados aos dos cidadãos de Lisboa:

A cidade do Rio de Janeiro teve a honra de ser a primeira que no Brasil recebeu estes privilégios por concessão de D. João IV em 1642, privilégios que muitas cidades da metrópole ainda não gozavam. Não tardou, porém, o rei a estender estes mesmos privilégios à cidade de S. Luiz do Maranhão (1645) em prêmio do heroico valor mostrado na expulsão dos holandeses, e à da Bahia (1646), o que os pediu para, sendo a capital, não ficar com honra inferior ás outras, e bem assim ás capitanias de Pernambuco e do Pará. Como outras cidades do Brasil pedissem dentro em breve com grande empenho e alcançassem estas mesmas prerrogativas, elas não se demoraram em se tornar vulgares e de pouco apreço (GALANTI, 1911a: 8).

Galanti faz outra menção à Revista do IHGB, como ao citar as queixas da Companhia de Comércio:

Continuando as queixas e as representações dos colonos, acabou finalmente a metrópole com essas providencias vexatórias do comboio e do máximo dos 
açúcares. Como, porém, as medidas do governo relativas à Companhia fossem sempre oscilantes e insuficientes, a antipatia dos brasileiros a respeito dela avultou pouco a pouco de tal modo, que o rei se viu obrigado a restringi-lhe a ação e privilégios até transformá-la primeiro em um tribunal régio com o nome de Junta do Comercio, e finalmente extingui-la de todo em 1720 (GALANTI, 1911a: 11).

Esta pesquisa nos leva ainda à reflexão sobre as atribuições do ofício de historiador, na época do "surgimento" da atividade, que ocorria concomitantemente à passagem para um novo regime no país. Neste contexto, indagamos: quais eram então as novas exigências para aqueles que se interessavam em escrever a história?

Rodrigo Turim responde a esta pergunta analisando três topoi que aparecem de forma recorrente nos textos historiográficos do século XIX: “a sinceridade, a cientificidade e a instrumentalidade" (2009: 14). E aponta-nos requisitos necessários ao historiador:

Estes elementos fazem parte da formalização da prática historiográfica, indo ao encontro do tipo de relação estabelecida entre o historiador, a história e o projeto de nação que se procurava instaurar. Três requisitos básicos dão forma ao ritual da escrita: o sentimento pátrio, o domínio técnico-científico e a pertinência do produto em relação ao seu uso (TURIN, 2009: 14).

A "escrita da história" de Galanti, no seu livro a História do Brasil é considerada "a primeira tentativa de sintetizar o passado do Brasil sob os novos tempos da República" (HRUBY, 2012:315). Ainda que seu modelo tenha sido refutado ou criticado, é possível aferir em suas pesquisas a consulta a diversos documentos como monografias, revistas, jornais, livros e fontes documentais.

Tal escrita também foi ao encontro dos requisitos a que se referia Turin (2009): o padre teve seu trabalho avaliado pelos consócios da Comissão de História do IHGB, para os quais seu compêndio havia sido "escrito com todo critério", indicando "profundos conhecimento da história da pátria", com votos para "ajudar-nos nas nossas tarefas e contribuir para o engrandecimento da história pátria" (MARQUES PINHEIRO, 1896: 300-301). Ao ser aceito no Instituto pelos seus livros, Galanti pretendia "promover o estudo da história pátria, a fim de estimular os jovens na imitação das façanhas gloriosas dos antepassados" (HRUBY, 2009: 60). 


\section{Matizes da construção da historiografia brasileira, uma possibilidade}

\section{Imagem I}

Padre Raphael Maria Galanti.

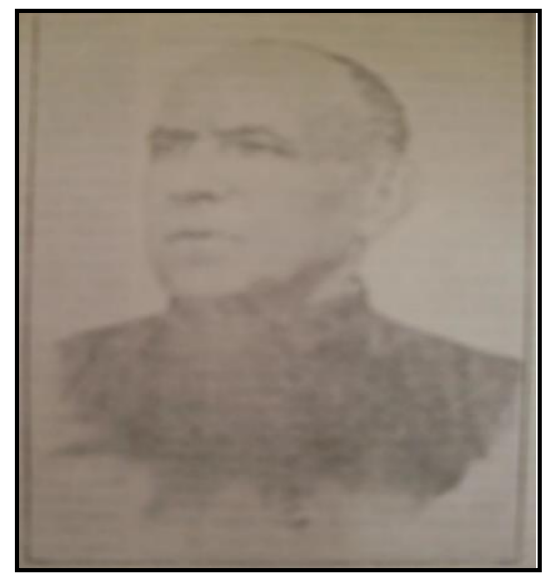

Fonte: Jornal Aurora Colegial, n. 94, p. 4

Professor no Colégio Anchieta em Nova Friburgo e sócio honorário do Instituo Histórico Geográfico Brasileiro de São Paulo; correspondente Instituto Histórico Geográfico Brasileiro; do Arqueológico Pernambucano e do Histórico de Santa Catharina e do da Bahia, Academia de letras de Pernambuco e do centro de Campinas (GALANTI, 1913: contracapa).

Seguindo algumas pistas da rede tecida pelo padre, notamos estratégias de aproximações intelectuais com José Luiz Alves (1895) e Muniz Tavares (1897), e de afastamentos, de Silva Neto (1893), Rocha Pombo (1917a e 1917b) e Varnhagen (1917), o que nos permitiu estudar o padre Galanti além do pouco que se tem escrito sobre ele.

A leitura das pesquisas aqui apresentadas nos sugeriu hipóteses sobre o que o levou a escrever e confrontar determinados autores, assim como a se inscrever em diversos institutos, onde representava a Ordem de Inácio de Loyola.

Padre Galanti nasceu na pequena cidade italiana de Ascoli-Piceno, em 15 de novembro de 1840. Ingressou na Companhia de Jesus em 1860 e, desde então, dedicouse aos estudos ${ }^{4}$, às viagens ${ }^{5}$ e à educação dos jovens nos colégios e seminários da

\footnotetext{
${ }^{4}$ Estudou além das disciplinas obrigatórias para o noviciado, Literatura e Filosofia. Disponível em: <http://www.jesuitasbrc.org.br/historia_jesuitabrasil.htm>. Acesso: 2 jul. 2009.

${ }^{5}$ Esteve em estados e capitais brasileiras como: Florianópolis, São Paulo, Pará e Rio de Janeiro; e em países como: Roma, Inglaterra e Bélgica. Disponível em: <http://www.ceara.pro.br/Instituto-site/Revapresentacao/RevPorAno/1906/1906-DezenoveDocssobrePalmares.pdf〉. Acesso: 30 abr. 2010.
} 
Companhia, participando de visitas pastorais no Norte do Brasil. Sua primeira obra, Compêndio de História do Brasil, foi publicada em 1896, tardiamente, visto que desde 1860 assumiu sua vocação docente na Ordem.

O padre, escritor e intelectual tornou-se conhecido no meio educacional e também historiográfico por conta dos livros de sua autoria. Para Circe Bittencourt, ele foi "o mais famoso escritor didático, dentre os jesuítas” (2004: 487). Lembremo-nos, ainda, das chancelas utilizadas para publicação e circulação das "obras de autores religiosos, em princípio, deveriam seguir os programas curriculares oficiais, entretanto sua circulação dependia da autorização eclesiástica" (BITTENCOURT, 2004: 487), sendo o Imprimatur uma forma de interferência no texto.

\section{Imagem II}

Imprimatur, no Tomo III do livro História do Brasil de Galanti.

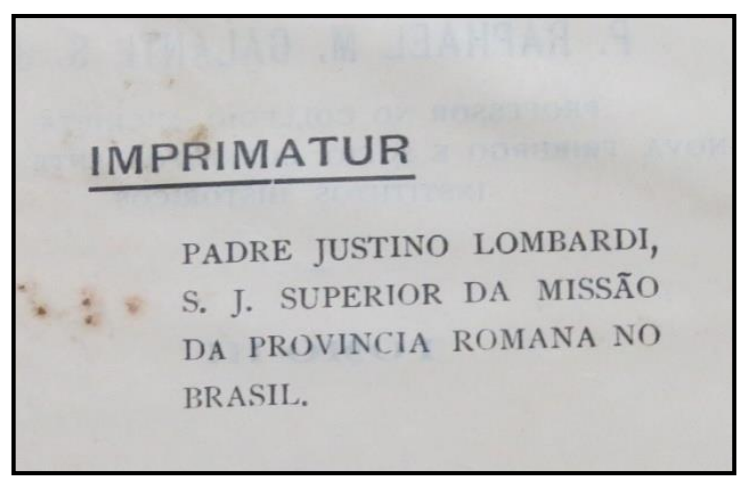

Fonte: Galanti, 1911a.

Era possível ver esta marca nas contracapas dos livros de Galanti, assinada e datada pela autoridade eclesiástica.

A interposição refere-se não apenas à produção didática, mas ao seu nome. Como assinalou o filósofo francês Michel Foucault, "o autor, ao dar seu nome próprio a uma obra, tem sobre a mesma responsabilidade, portanto, sujeito às sanções, neste caso, nessa perspectiva, a função-autor que necessariamente estabelece vínculos diversos com a obra e cria identidades" (1992: 478).

Nesse sentido, a escrita de Padre Galanti, seja para o conhecimento dos alunos ou para o convencimento dos leitores em geral, pretendeu causar "grandes efeitos", pelo menos no que tangia à defesa da Ordem. Seguindo as proposições de Sirinelli, pretendemos "refletir sobre a função do intelectual em dado lugar, considerando tanto os aspectos socioeconômicos quanto simbólicos, de modo a compor uma espécie de 
cartografia do meio intelectual, capaz de identificar posições, relações e deslocamentos" (SIRINELLI, 2003: 262). Almejamos refletir sobre o papel do jesuíta Raphael Maria Galanti na construção de um Brasil moderno e de seu projeto de nação. Assim como para François Sirinelli (1996) é necessário "pensar os intelectuais como criadores e mediadores culturais e como atores do político, relativamente engajados na vida da cidade e/ou nos locais de produção e divulgação do conhecimento e promoção de debates" (1996: 263), para nossa pesquisa tornou-se necessário pensar para além do engajamento de Galanti à época em que seus livros foram editados (GALANTI, 1910, 1911a, 1911b, 1913, 1896), assim como sua entrada e participação em institutos, por exemplo, no IHGB, com sua candidatura proposta em 1896, são focos centrais da nossa atenção.

As nuances da educação e da historiografia, nas quais a participação do padre é relevante, ampliam ainda mais nosso horizonte de análise. No sentido que esclarece Forquin,

Se toda educação é sempre educação de alguém por alguém, ela supõe sempre também necessariamente, a comunicação, a transmissão, a aquisição de alguma coisa: conhecimentos, competências, crenças hábitos, valores, que constituem o que se chama precisamente de "conteúdo" da educação [...] este conteúdo que se transmite na educação é sempre alguma coisa que nos precede, nos ultrapassa e nos institui enquanto sujeitos humanos, pode-se perfeitamente dar-lhe o nome cultura (1993: 10).

Já pelos idos do final do Império e início da Primeira República, um novo período político vivido no país trouxe em seu bojo movimentos nos campos político, cultural e educacional, sendo o último marcado por efervescentes e calorosas discussões sobre vários projetos e reformas. Em 1910, ocorria novamente a supressão da Companhia de Jesus, ${ }^{6}$ dessa vez em Portugal.

É dentro do contexto da Primeira República, quando a Constituição de 1891estabeleceu, entre outras medidas, o presidencialismo e a separação entre Estado e Igreja, que apreendemos a discussão e a escrita historiográfica notada no artigo. A República trouxe consigo ideais modernos, entre eles a preocupação com a educação

\footnotetext{
${ }^{6}$ As supressões citadas são a de 1834 e 1910, compreendendo que se não ocorreram, diretamente, pelos mesmos motivos de 1759, dado que as supressões têm circunstâncias diferentes, estavam todas inseridas em complexos movimentos políticos. A de 1834, com ápice do movimento liberal português, e a de 1910 com a Proclamação da República portuguesa (MENDONÇA, 2010: 17).
} 
formal, o ensino religioso católico perdeu privilégios, dentre os quais não poder ensinar religião nas escolas públicas, quando foi decretado o ensino laico. Assim, descortinamos nossos primeiros vestígios sobre o intelectual que, a nosso ver, esteve na defesa de sua Ordem e do ensino católico, por meio de "sua pena", avistando daí a grande importância das suas obras.

O conjunto de texto sobre Galanti, aqui selecionados, nos permite visualizar uma interessante disputa em torno do passado desejado para a nação brasileira e das formas necessárias para uma adequada escrita da história nacional. Tal momento foi marcado por tensões e disputas em busca de um modelo canônico da escrita da história. Dessa forma, viria a se constituir uma memória que tenderia a apagar esse momento, a fim de consagrar a lembrança de um modelo único e coeso para a escrita da história oitocentista no Brasil. Precisaríamos de muito mais que um artigo para problematizar um intelectual envolvido num projeto educacional - como é o caso de Galanti- pois, à medida que tentamos (re) construir a história do intelectual, tocamos no matiz a que Sirinelli chama degradé, aquele mesmo que propõe um "passear" entre a ideologia, cultura política e mentalidades coletivas. A análise acerca do pensamento, projeto educacional e político de que participara, quem eram seus pares, a quem confrontava e seus motivos nos é vital, porque “chaque groupement intellectuel naît et se développe sous un micro clima particulieret c'était la deuxième acception proposée du terme sociabilité" (SIRINELLI, 1988: 633). Torna-se necessário, portanto, investigar a atmosfera e a sociabilidade vivida por Galanti, os consócios dos Institutos dos quais participou, outros intelectuais e historiadores da época, o que o atrai a um determinado grupo e o afasta de outro, assim como seu comprometimento, pois a rede social, da qual fazia parte nos leva a um caminho para o indivíduo, para poder (re) pensá-lo.

Ao analisarmos seu discurso de posse no Instituto Histórico Geográfico Brasileiro revelamos o teor das ideias contidas em seus livros, principalmente as que trataram diretamente da História do Brasil:

A Companhia deseja desvelar-se em benefício do Brasil não menos do que fez em outros tempos. Deseja a Companhia promover a boa educação da mocidade, porque a mocidade é a esperança da Pátria; deseja promover o progresso das letras e das ciências, porque delas em grande parte depende a prosperidade da nação; deseja em particular promover o estudo de História Pátria afim de excitar os jovens a imitar as façanhas gloriosas de seus 
antepassados. Falo das Façanhas gloriosas que não são conhecidas porque o "estudo de História pátria entre nós ainda está pouco generalizada" (GALANTI,1896: 316-318).

A construção e a interpretação que delineamos remetem-nos a uma variação de escalas $^{7}$, que nos permite passear pela escrita do padre, em um discurso individual, assim como pela sua rede sociabilidade e por historiadores e intelectuais citados, utilizados ou confrontados por Galanti. Deste trecho em que inicialmente, de longe, aparecem somente o padre e o professor, defendendo com seus argumentos a atuação da sua Ordem e a "boa educação" para mocidade, a fim de alavancar a prosperidade da nação, podemos inferir algumas pistas do intelectual que foi o padre Galanti, ao encorajar os jovens a assemelharem-se às grandes façanhas. Notamos, também, uma crítica à História do Brasil, parecendo faltar-lhe, ainda, um maior esforço para escrita e circulação da história oficial da nação.

Seus livros, mesmo sendo dedicados à "boa educação" da juventude, ou seja, como didáticos, têm nos mostrado uma variedade de conceitos e considerações que o autor faz em torno da historiografia da época, principalmente, no que diz respeito à forma pela qual a mesma é trabalhada no Brasil, como deixou claro no seu discurso de posse no IHGB.

O viés cronológico de seu trabalho é relevante. As façanhas gloriosas são lembradas por padre Galanti, por exemplo, no Compendio de História do Brasil, divido em cinco volumes, que se inicia pela história e conquistas de Portugal, intitulado pelo autor de pré-história do país. No volume I, publicado em 1896, há uma divisão em três épocas, a saber: “Época I: 1500-1549, Época III: 1549-1581, Época IV: 1581-1624”. Também nos chama atenção a abordagem feita no último volume do compêndio que cita a Proclamação da República, em 1889, podendo-se assim notar o tema atualizado para a época, visto que a data da primeira edição do livro é de 1905.

Sob qual ângulo o padre compreende a história? Sua concepção de História é delimitada com mais precisão nas noções preliminares do livro Compendio de História Universal, como "a narração autêntica e bem ordenada dos acontecimentos memoráveis que pertencem ao gênero humano" (GALANTI, 1894: 15). Nesse livro, o padre

\footnotetext{
${ }^{7}$ Variação de escala, fazendo referência à micro-história seria não a escolha entre uma escala, mas a sua variação, esta sim é analisada por Jaques Revel como fundamental para "passar de uma história para outra (e, por que não, para várias outras) (REVEL, 1998: 38).
} 
novamente aponta como se divide e se define a História: "Universal (todos os países), Geral (todos os países, mas numa só época) e particular (limita-se a alguns anos, uma só província ou guerra)" (GALANTI, 1894: 15).

A esta narração autêntica acrescentamos alguns conceitos que parecem permear a escrita e o pensamento historiográfico de padre Galanti, quando ele indica as diversas maneiras de se escrever ou compreender a história:

\begin{abstract}
"Biografia: história observada da vida de uma pessoa se for resumida recebe o nome de Memória", "Anais: narração simples e concisa de factos dispostos anos por ano, sem ordenamento, sem ligação diferem da História porque esta muitas vezes omite meses e dias" e "Cronologia: a ciência que se ocupa em averiguar e registrar as datas do acontecimento" (1894: 16).
\end{abstract}

Elege também aponta a metodologia e as fontes utilizadas para escrever história:

Etnográfico, sincrônico e misto e Diretas - documento/monumento escritos com intuito de transmitir à posterioridade os fatos memoráveis. Indiretas - que examinados com auxílio de crítica nos "revelam alguma notícia acerca da vida do homem" nas diversas áreas: geografia, linguísticas, estatuas, pinturas... As obras de arte. Tradições orais (GALANTI, 1894: 16).

É sob esse prisma que os livros do padre Galanti foram construídos. No único volume dedicado às crianças, Breve História do Brasil destinada às crianças do curso preliminar (1913), se observam as mesmas divisões das épocas encontradas no Compendio de História do Brasil. Também em Lições de História do Brasil (1895) há uma escrita parecida, embora não se tratasse de obra destinada ao público infantil. Porém, a obra apresenta uma preocupação com a internalização dos conteúdos, o que se destaca na existência de um "questionário" ao fim de cada capítulo, com perguntas minuciosas e detalhadas sobre o conteúdo. O ato de interiorizar faz parte da metodologia jesuíta, compreendida por Franca como "os processos didáticos adotados para a transmissão de conhecimentos, quanto aos estímulos pedagógicos postos em ação para assegurar o êxito do esforço educativo" (1952: 56). Assim, antes da preleção nas aulas, o Ratio Studiorum ${ }^{8}$

${ }^{8}$ Método de estudos utilizados pela Companhia de Jesus (FRANCA, 1952). 
preconizava os exercícios cotidianos da memória. Uma pista de que os jesuítas "modernizaram" na busca da manutenção da tradição.

\section{Alguns apontamentos...}

Em meio a um efervescente e crescente mercado de livros, notadamente os de história, os livros do padre Raphael Maria Galanti circularam por várias capitais brasileiras ${ }^{9}$ : São Paulo, Rio de Janeiro, Pernambuco e Porto Alegre.

Pesquisas como a de Patrícia Hansen (2007) mostram a intenção e a finalidade dos textos produzidos no Brasil, cujos temas eram voltados para a infância, indicando o período da Proclamação da República até início dos anos 1920 como um contexto de instabilidades social, econômica e política. Neste contexto, tais escritos cívicos:

Pretendiam exercer uma pedagogia moral, assumiram, além da finalidade principal e de forma complementar a ela, a função de inculcar nas crianças novas regras de civilidade, procurando impor um padrão de hábitos e comportamentos aos quais os indivíduos deveriam se condicionar, e que sintetizavam um ideal de homem, representado em potencial na infância brasileira (HANSEN, 2007: 3).

Estudos desse período têm mostrado que os autores dos livros de história, seja para crianças ou para juventude, pretendiam formar uma escola de cidadãos "civilizados". Hansen (2007) compreende que houve uma ruptura com a escrita religiosa em consequência dos ideais republicanos. Porém, tanto os livros de outros autores didáticos religiosos, quanto os de padre Galanti, parecem-nos, ainda, bem influenciados por essa perspectiva e apropriando-se do catecismo católico.

Neste estudo notamos questões e possibilidade que podem nos levar ao padre e a sua obra, que permitam a compreensão da circulação, do itinerário e da sociabilidade construída por esse intelectual. Este movimento da pesquisa tem sido relevante para pensar questões maiores, com as quais não encerramos este artigo, mas tocamos num caminho a seguir: Seriam esses matizes da construção do pensamento da historiografia brasileira? Galanti pode ser analisado como intelectual ou apenas autor de livros didáticos?

${ }^{9}$ Como se pode perceber na própria capa do livro do padre, numa espécie de propaganda. 
Fontes

ALVES, José. Luiz. (1895) Os claustros e o clero no Brasil. Revista do Instituto Histórico e Geográfico Brasileiro, Rio de Janeiro, t. 57, parte 2.

GALANTI, Raphael Maria (1897). Posse do pe. Rafael Galanti. Rio de Janeiro: IHGB. (1895). Lições de Historia do Brazil. São Paulo: Typ. da Industrial de São Paulo. (1896-1905). Compendio de Historia do Brasil (Tomos I, II, III, IV e V). São Paulo: Typ. da Industrial de São Paulo.

(1894). Compendio de Historia Universal. São Paulo: Typ. da Companhia Industrial.

(1911a). História do Brasil. t. III. São Paulo: Duprat\& Comp.

(1911b). Jornal Aurora Colegial, Edição maio. Rio de Janeiro: Nova Friburgo.

(1913). Breve Historia do Brasil destinada as creanças do curso preliminar. São Paulo: Duprart \& Comp.

(1895). Lições de Historia do Brazil. São Paulo: Typ. da Industrial de São Paulo.

LIMA, Oliveira (1918/1919). Documentos completos sobre a Confederação do Equador. Revista do Instituto Histórico e Geográfico Brasileiro, t. 83, pp. 351-426.

MARQUES PINHEIRO, Francisco Batista. Actas das Sessões de 1896. Revista do Instituto Histórico e Geográfico Brasileiro, t. 59, parte 2, pp. 300-301.

POMBO, José Francisco da Rocha (1917a). História do Brasil. Rio de Janeiro: J. Fonseca Saraiva/Benjamin de Aguila, $10 \mathrm{v}$.

(1917b). História do Brasil, ilustrada. vol. X. Parte suplementar: documentos para a história do primeiro decênio da República. Rio de Janeiro: Benjamin de Aguila.

SILVA NETO, Joaquim. José. Gomes. da (1893). História das mais importantes minas de ouro do Estado do Espírito Santo. Revista do Instituto Histórico e Geográfico Brasileiro, Rio de Janeiro, t. 55, parte 2.

TAVARES, Francisco. Muniz. (1897). História da revolução em Pernambuco em 1817. Revista do Instituto Histórico e Geográfico Brasileiro, t. 60, parte 1, pp. 103-291.

VARNHAGEN, Francisco Adolfo de (1844). Primeiro juizo: submettido ao Instituto Historico e Geographico Brazileiro pelo seu socio Francisco Adolpho de Varnhagen, acerca de "Compendio de Historia do Brazil" pelo Sr. José Ignacio de Abreu e Lima. Revista do Instituto Histórico e Geográfico Brasileiro. Rio de Janeiro, v. 6, t. 6, pp. 60-83.

(1917). Historia da independencia do Brasil: até ao reconhecimento pela antiga metropole, comprehendendo, separadamente, a dos successos occorridos em algumas provincias até essa data.Rio de Janeiro: Imprensa Nacional.

\section{Referências bibliográficas}

ALMEIDA, Adir da Luz (2010). Viajando pelo agridoce toque da Ciência. O serviço de ortofrenia e de higiene mental no Rio de Janeiro de 1930: seus efeitos na escola, família e comunidade. São Paulo: USP.

BITTENCOURT, Circe. M. (2004) Autores e editores de compêndios e livros de leitura (1810-1910). Educação e Pesquisa, vol. 30 n. 3, pp. 474-491, set./dez. 
CERTEAU, Michel de (1996). Espaço Privados. In: CERTEAU, Michel de; MAYOL, Pierre; GARD, Luce. A invenção do cotidiano: morar, cozinhar. vol.2 Petrópolis, RJ: Vozes, pp. 203-207.

(2002). A escrita da História. Trad. Maria de Lourdes Menezes. Revisão Técnica: Arno Vogel. RJ: Forense-Universitária.

CHARTIER, Roger (1998). As utilizações do Objecto Impresso (Séculos XV-XIX). Trad. Ida Boavida. Portugal: DIFEL.

(1999). A ordem dos livros: leitores, escritores e bibliotecas na Europa entre os séculos XIV e XVIII. Trad. Mary Del Priore. Brasília. 2 ed. Brasília: EdUNB.

CONTI, Maria Lígia (2011). O personagem negro em lições de história no Brasil: olhares oitocentistas. Dissertação (Mestrado em Educação). Universidade de Sorocaba, SP.

DARNTON, Robert (1986). O grande Massacre dos gatos e outros episódios da história cultural francesa. Tradução Sônia Coutinho. 2 ed. Rio de Janeiro: Graal. (1990). O beijo de Lamourete. Mídia, cultura e revolução. São Paulo: Companhia das Letras.

FRANCA S.J., Leonel (1952). Ratio Studiorum: o método pedagógico dos jesuítas. Rio de Janeiro: Agir.

FORQUIN, Jean Claude (1993). Escola e cultura: as bases epistemológicas do conhecimento escolar. Porto Alegre, RS: Artes Médicas.

FOUCAULT, Michael (1992). O que é o autor? [Lisboa]: Ed. Passagens.

GOMES, Ângela M. de Castro (1996). Os historiadores e autores de livros. In: GOMES, Ângela M. de Castro. História e historiadores. Rio de Janeiro: FGV, pp. $27-55$.

HANSEN, Patrícia (2007). Brasil, um país novo: literatura cívico-pedagógica e a construção de um ideal de infância brasileira na Primeira República. Tese (Doutorado em História Social). Universidade de São Paulo, São Paulo.

HRUBY, Hugo (2012). O século XIX e a escrita da história do Brasil: diálogos na obra de Tristão de Alencar Araripe (1867-1895). Porto Alegre.

INSTITUTO. Disponível em: <http://www.ceara.pro.br/Instituto-site/Revapresentacao/RevPorAno/1906/1906-DezenoveDocssobrePalmares.pdf >. Acesso: 30 abr. 2010.

JESUÍTAS. Disponível em: <http://www.jesuitasbrc.org.br/historia_jesuitabrasil.htm>. Acesso: 2 jul. 2009.

MENDONÇA, Ligia Bahia (2010). O silêncio da ação: jesuítas no Brasil pós-Reforma Pombalina. UERJ - Rio de Janeiro.

MENONCELLO, Aline Michelini (2013). Laudo ou Sentença? A decisão de Pedro Lessa da data comemorativa da Confederação do Equador. $7^{o}$ Seminário Brasileiro de História da Historiografia - Teoria da história e história da historiografia: diálogos Brasil-Alemanha. Ouro Preto: EdUFOP, pp. 1-10.

PAULA, Leandro S. (2014). América Portuguesa e educação no século XVIII: Um balanço historiográfico. XII Encontro Estadual de História ANPUH. História, verdade e ética. Universidade Vale dos Sinos, São Leopoldo, RS, pp. 1-16.

PINA, Maria Cristina Dantas (2006). A questão racial no ensino secundário baiano: problematizando o livro didático de história. Anais do III Encontro Estadual de História: Poder, Cultura e Diversidade, Salvador, pp. 1-25.

REVEL, J. (Org.) (1998). Jogos de escala: a experiência da microanálise. Rio de Janeiro: FGV.

SANTOS, Ivan Norberto dos (2009). A historiografia amadora de Rocha Pombo: embates e tensões na produção historiográfica brasileira da Primeira República. Rio de Janeiro: UFRJ/ IFCS/ PPGHIS. 
SIRINELLI, François (1988). Génération intellectuelle. Khâgneux et normaliens dans l'entre-deux-guerres. Paris: Fayard.

(2003). Os intelectuais. In: REMOND, Rena. Por uma História Política. 2 ed. Tradução Dora Rocha. Rio de Janeiro: Fundação Getúlio Vargas, pp. 231-269.

VILLALTA, Luiz Carlos (2001). O Livro Didático de História no Brasil: perspectivas de abordagem. Revista: Pós - História, Assis, SP, vol. 9, pp. 39-59.

Artigo recebido em 23 de março de 2015.

Aprovado em 14 de junho de 2015.

DOI: $10.12957 /$ intellectus.2015.18796 